\title{
Estimular para prevenir numa abordagem histórico- cultural: propostas para a educação infantil
}

\author{
Stimulate to prevent in a historical-cultural approach: proposals for \\ early childhood education
}

\author{
Caio Morais ${ }^{1}$ \\ Jamile Chastinet ${ }^{2}$ \\ Camila Borges ${ }^{3}$
}

\begin{abstract}
RESUMO
A aquisição de aprendizagens complexas, como a alfabetização, só pode acontecer porque os anos anteriores preparam as crianças para tanto. A educação infantil precisa ser responsável por essa preparação e prevenção de dificuldades futuras de aprendizagem. O presente artigo tem por objetivo apresentar propostas de parâmetros fundamentados na Psicologia Históricocultural que podem ser utilizados no âmbito da educação infantil, favorecendo a preparação das crianças para a entrada no ensino fundamental e prevenindo possíveis dificuldades no processo de aprendizagem. Baseia-se na concepção de desenvolvimento psicológico dessa abordagem e na sua visão do funcionamento neuropsicológico. Apresenta proposta de aplicação prática desses conceitos em contexto escolar.
\end{abstract}

Palavras-chave: Desenvolvimento infantil. Neuropsicologia histórico-cultural. Prevenção. Educação Infantil.

\begin{abstract}
According to Vygotsky, the acquisition of complex learning, such as literacy, can only happen because previous years prepare children for it. Early childhood education must be responsible for this preparation and, consequently, prevent future learning difficulties. The purpose of this article is to present proposals for parameters based on historical-cultural psychology that can be used in the field of early childhood education as a methodological resource for teachers' work, favoring the preparation of children for entering elementary education and preventing future difficulties in the process of learning. It is based on the psychological development conception of this approach and on its vision of neuropsychological functioning. It presents a proposal of practical application of these concepts in school context.
\end{abstract}

Keywords: Child development. Historicalcultural neuropsychology. Prevention. Child Education.

\footnotetext{
1 Psicólogo. Mestre em Diagnóstico e Reabilitação Neuropsicológica, pela Benemérita Universidade Autônoma de Puebla (México). Sócio fundador e administrador do Instituto Luria de Neuropsicologia (Salvador-BA). Professor da pós-graduação em Neuropsicologia da Faculdade Ruy Barbosa (Salvador-BA). Assessor de acessibilidade da SECADI/MEC.

2 Psicóloga. Mestre em Diagnóstico e Reabilitação Neuropsicológica, pela Benemérita Universidade Autônoma de Puebla (México). Sócia fundadora do Instituto Luria de Neuropsicologia (Salvador-BA). Professora da pós-graduação em Neuropsicologia da Faculdade Ruy Barbosa (Salvador-BA). Psicóloga do CEPRED (Salvador-BA).

3 Psicóloga pela Faculdade Ruy Barbosa (Salvador, Bahia). Mestranda em Diagnóstico e Reabilitação Neuropsicológica, pela Benemérita Universidade Autônoma de Puebla (México).
} 


\section{Introdução}

Os Parâmetros Curriculares Nacionais para o Ensino Fundamental (BRASIL. Ministério da Educação, 2000) determinam que a proposta de organização do conhecimento para esta etapa escolar deve necessariamente incluir o estudo da Língua Portuguesa e da Matemática (além de outras disciplinas). De acordo com a terceira versão da Base Nacional Comum Curricular (BNCC) (BRASIL. Ministério da Educação, 2017), ao longo dos dois primeiros anos do Ensino Fundamental, a ação pedagógica deve ter, entre outros, o objetivo de alfabetizar e o compromisso com o desenvolvimento do "letramento matemático".

Vigotsky (1998), discorrendo sobre a grande complexidade do processo de aquisição da linguagem escrita por parte da criança, assevera que está ocorre apenas como resultado de um longo processo de desenvolvimento das funções superiores do comportamento infantil, integrando uma história complexa que antecede o estudo da escrita propriamente dito na escola. $\mathrm{O}$ mesmo acontece com o desenvolvimento das operações aritméticas (VIGOTSKY, 1995). Disso decorre a ideia de que o processo de aprendizagem de conceitos científicos complexos, a partir da entrada no Ensino Fundamental, só pode acontecer como resultado do desenvolvimento anterior da criança durante os anos da Educação Infantil.

A mesma ideia se consubstancia na promulgação da BNCC, segundo a qual o termo "educação pré-escolar" apresenta a concepção de uma etapa anterior à educação formal, independente dela e preparatória para a escolarização, embora em 1996 a Lei de Diretrizes e Bases da Educação Nacional (LDB) tenha introduzido uma modificação nessa noção ao fazer com que a Educação Infantil passasse a integrar a Educação Básica, localizando-se no mesmo patamar do Ensino Fundamental e o Médio.

Observa-se, então, a importância que os anos da Educação Infantil têm na preparação da criança para a entrada no Ensino Fundamental. Nesse período, é obrigação da escola e dos professores garantir a estimulação da aquisição das habilidades infantis necessárias para o aprendizado escolar posterior. Ao mesmo 


\section{Obütchénie}

tempo, tal labor deve ter como consequência a prevenção de problemas futuros no processo de ensino-aprendizagem. Para tanto, são necessários parâmetros capazes de instrumentalizar os profissionais da Educação Infantil a observar, analisar, compreender e estimular o desenvolvimento e o processo de ensinoaprendizagem para esse fim.

$\mathrm{Na}$ teoria histórico-cultural moderna, Psicologia e Neuropsicologia se integram (TOOMELA, 2014). Por este motivo, os parâmetros de trabalho para o Ensino Infantil devem ser tanto psicológicos, quanto neuropsicológicos, além de pedagógicos. Desta forma, este trabalho objetiva apresentar propostas de parâmetros fundamentados nas contribuições dos teóricos da Psicologia Histórico-cultural para apoiar professores da Educação Infantil no trabalho de preparação das crianças em idade pré-escolar para a entrada no Ensino Fundamental e, ao mesmo tempo, para a prevenção de dificuldades futuras.

Para tanto, utilizou-se o método de estudo bibliográfico, especialmente de publicações de autores da Psicologia Histórico-cultural. Parte-se dos princípios do desenvolvimento psicológico infantil a partir de conceitos como os de plano social de desenvolvimento, idade psicológica, situação social do desenvolvimento, neoformações, linha geral do desenvolvimento e atividade-guia. A esta visão, que integra psiquismo e contexto social, acrescentam-se conceitos neuropsicológicos, tais como: sistema funcional complexo, fatores neuropsicológicos, avaliação neuropsicológica qualitativa e diagnóstico por observação. As reflexões conduzidas a partir da conexão entre esses eixos centrais aqui abordados buscam servir aos profissionais da educação como sugestões de parâmetros teóricos, norteadores de uma prática concreta em contextos educacionais.

\section{Desenvolvimento psicológico infantil}

De acordo com Zaporozhets (1986), fundamentando-se nos postulados sobre a herança social e o legado da cultura material e espiritual criados pela sociedade, assim como propostos pelos clássicos do marxismo-leninismo, e apoiando-se numa série de investigações teóricas e experimentais, psicólogos soviéticos construíram as bases de uma teoria do desenvolvimento psíquico 
infantil. Estabeleceram, então, que no desenvolvimento da criança há uma forma particular de experiência que adquire um papel dominante: a social. No processo de assimilação desta, ocorre a aquisição de diferentes conhecimentos e habilidades, o desenvolvimento de capacidades e a formação da personalidade (ZAPOROZHETS, 1986). Neste contexto, o termo "social" considera a cultura como um produto da vida e da atividade grupal do ser humano, considerando, portanto que o cultural é social. Assim, o desenvolvimento cultural da conduta leva diretamente ao plano social do desenvolvimento (VIGOTSKY, 1995). O meio social não é simplesmente uma condição externa, mas a verdadeira fonte do desenvolvimento humano. A assimilação da experiência social não ocorre de maneira passiva, mas ativa: as crianças a dominam pelo fato de ela estar plasmada nos instrumentos de trabalho, na linguagem, nas obras científicas e artísticas, com ajuda dos adultos durante o processo de comunicação/interação com aqueles que as rodeiam (ZAPOROZHETS, 1986).

Durante o desenvolvimento, a criança assimila as formas sociais da conduta e as transfere a si mesma, sendo regulada pela aquisição dos signos. Inicialmente, este é um meio de relação social, de influência sobre os demais, que apenas depois se transforma numa forma de controle sobre si mesmo. A criança começa a aplicar a si própria as maneiras de comportamento que, inicialmente, outros aplicavam a ela (VIGOTSKY, 1995). Isso acontece ao longo de três etapas do desenvolvimento da conduta. A primeira é constituída pelos instintos, ou seja, o fundo inato, hereditário, dos procedimentos da conduta. A segunda é a dos reflexos condicionados, isto é, das reações condicionadas aprendidas e adquiridas na experiência pessoal. A terceira é a etapa do intelecto, ou reações intelectuais, que realiza a função de adaptação às novas condições (VIGOTSKY, 1995). De acordo com Vigotsky (1995), o estudo dessas mudanças e dessas novas formas de conduta torna possível a descoberta de sinais de desenvolvimento no verdadeiro sentido da palavra. Pode-se, então, convertê-los em parâmetros para o acompanhamento da maturação infantil e para a preparação da criança à entrada ao Ensino Fundamental. 


\section{Obutchénie}

\subsection{Periodização do desenvolvimento em idades psicológicas}

Seguindo essa noção peculiar sobre o desenvolvimento, Vigotsky (1996), propôs o conceito particular de idade psicológica, que se refere a formações globais e dinâmicas que caracterizam os períodos do desenvolvimento. $\mathrm{Na}$ infância, as idades psicológicas propostas pelo autor são: "Primeiro ano" (de zero a um ano), "Primeira infância" (de um a três anos), "Pré-escolar" (de três a seis anos) e "Escolar" (de seis a doze anos).

O desenvolvimento da criança, em cada uma das idades psicológicas anteriormente citadas, transcorre a partir de linhas centrais e acessórias do desenvolvimento, que derivam respectivamente de novas formações centrais e parciais (VIGOTSKY, 1996). Destaca-se que o ponto de partida para todas as mudanças dinâmicas que ocorrem em cada idade psicológica é a interação social da criança (com os pais, a família, os coetâneos, entre outros), o que delimita a situação social de seu desenvolvimento (VIGOTSKY, 1996; QUINTANAR; SOLOVIEVA, 2008). A experiência cultural que a criança adquire é determinada por duas linhas do desenvolvimento psicológico: uma afetivo-emocional e outra técnico-operacional, sendo que ambas se alternam entre as idades psicológicas, mantendo uma interação dinâmica de tal modo que quando uma delas é a linha geral a outra opera como linha subordinada (SOLOVIEVA; QUINTANAR, 2012). Quando a linha geral é afetivo-emocional, o interesse da criança está voltado para as relações e experiências sociais. Se a linha geral é técnico-operacional, o interesse estará vinculado à experiência prática.

Portanto, em cada idade existem alguns aspectos-chave que ajudam a caracterizar o desenvolvimento da criança: a situação social do desenvolvimento (que caracteriza as condições particulares de cada idade), as neoformações básicas (que são processos e fenômenos da psique que não existiam anteriormente e surgiram como resultado do desenvolvimento em uma determinada idade) e a linha geral do desenvolvimento (que se relaciona com o objeto de interesse da criança, que pode ser social ou prático) (QUINTANAR; SOLOVIEVA, 2008). Além disso, em cada etapa encontra-se sempre uma nova formação central como uma espécie de orientação para todo o processo de desenvolvimento e que caracteriza a 
reorganização da criança sobre uma base nova: a atividade-guia (VIGOTSKY, 1996).

A atividade-guia é aquela que, dentre tantas outras que a criança realiza, é a principal por determinar as mudanças básicas em sua psique, preparando-a para um nível mais elevado do desenvolvimento (VIGOTSKII; LURIA; LEONTIEV, 1988; VIGOTSKY，1996; QUINTANAR; SOLOVIEVA, 2008). As formações psicológicas novas, ou neoformações, que aparecem no final de cada etapa promovem mudanças no sistema de relação do sujeito com a realidade externa e consigo mesmo, e indicam a necessidade de passar à etapa seguinte (VIGOTSKY, 1996). Em resumo, cada idade psicológica está caracterizada por uma atividade-guia, neoformações, uma situação social e linhas do desenvolvimento (ver Quadro 1).

Quadro 1 - Idades, situação social do desenvolvimento, atividade guia, neoformações e linha geral do desenvolvimento para cada etapa do desenvolvimento infantil de 1 a 6 anos segundo a abordagem histórico-cultural.

\begin{tabular}{|c|c|c|c|c|}
\hline Período & $\begin{array}{c}\text { Situação } \\
\text { social }\end{array}$ & Atividade guia & Neoformações & $\begin{array}{c}\text { Linha } \\
\text { geral }\end{array}$ \\
\hline $\begin{array}{l}1^{\circ} \text { ano } \\
(\text { de } 0 \text { a } 1 \text { ano) }\end{array}$ & Nós & $\begin{array}{l}\text { Comunicação } \\
\text { emocional } \\
\text { direta com os } \\
\text { adultos }\end{array}$ & $\begin{array}{l}\text { - Preensão como base das } \\
\text { ações humanas com as } \\
\text { coisas } \\
\text { - Série de ações perceptivas } \\
\text { - Marcha voluntária } \\
\text { - Linguagem }\end{array}$ & $\begin{array}{l}\text { Afetivo- } \\
\text { emocional }\end{array}$ \\
\hline $\begin{array}{l}\text { "Primeira } \\
\text { infância" } \\
\text { (de } 1 \text { a } 3 \text { anos) }\end{array}$ & Proto-eu & $\begin{array}{l}\mathrm{Jogo}^{4} \text { de } \\
\text { manipulação } \\
\text { com objetos }\end{array}$ & $\begin{array}{l}\text { - Surge na linguagem a } \\
\text { designação com sentido das } \\
\text { coisas } \\
\text { - Percepção categorial } \\
\text { generalizada do mundo } \\
\text { objetal } \\
\text { - O pensamento concreto das } \\
\text { ações. } \\
\text { (neoformação central: “Eu”) }\end{array}$ & $\begin{array}{l}\text { Técnico- } \\
\text { operacional }\end{array}$ \\
\hline $\begin{array}{l}\text { "Pré-escolar" } \\
\text { (de } 3 \text { a } 6 \text { anos) }\end{array}$ & $\begin{array}{l}\mathrm{Eu} \\
\text { reflexivo }\end{array}$ & $\begin{array}{l}\text { Atividade de } \\
\text { jogo de papéis }\end{array}$ & $\begin{array}{l}\text { - Imaginação } \\
\text { - Função simbólica } \\
\text { - Consciência das relações } \\
\text { humanas }\end{array}$ & $\begin{array}{l}\text { Afetivo- } \\
\text { emocional }\end{array}$ \\
\hline
\end{tabular}

\footnotetext{
${ }^{4}$ Neste trabalho, optou-se por utilizar os termos "jogo" e "brincar" como sinônimos, sendo que foi dada preferência ao primeiro. Isto porque as principais fontes para o tema estão em espanhol e utilizam a palavra "juego", além de que facilita a denominação dos estágios, como em "jogo de manipulação" ou "jogo simbólico".
} 


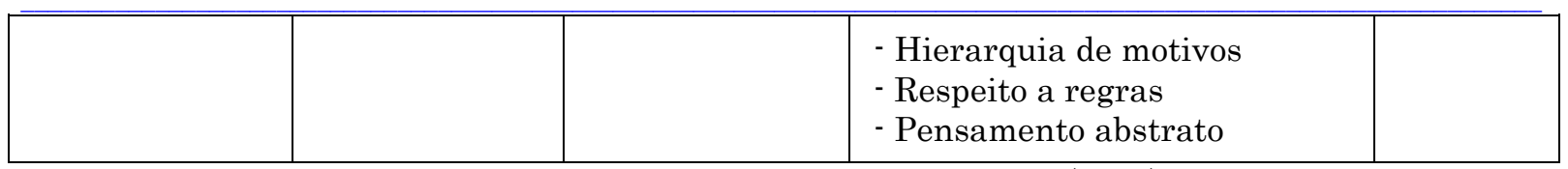

Fonte: Adaptado de Solovieva e Quintanar (2012).

Desta forma, a tese fundamental no desenvolvimento psicológico da criança é que seu conteúdo se expressa em avanços qualitativos que ocorrem dentro da atividade que ela realiza conjuntamente com os adultos, na comunicação com eles e sob sua direção, e também na atividade contígua com outros pequenos. Assim, conclui-se que o desenvolvimento é mediado, desde o começo, pela educação e pelo ensino (DAVIDOV, 1988). Segundo Vygotski (1996), aquilo que a criança é capaz de fazer em uma ação conjunta, colaborativa, mediada pelo adulto, configura sua Zona de Desenvolvimento Proximal (ZDP) e, portanto, refere-se a processos que se encontram em maturação. Aquilo que ela faz hoje com auxílio do adulto, amanhã fará por conta própria, passando a conformar sua Zona de Desenvolvimento Real (ZDR).

O desenvolvimento infantil pode ser afetado tanto por aspectos externos, como internos. As influências externas, como uma interação social insuficiente ou deficiente, podem conduzir a um decremento do nível de maturação psicológica. As influências internas, como um retardo na formação da base orgânica dos sistemas funcionais, podem manifestar-se como um déficit dos componentes neurológicos e eletrofisiológicos (QUINTANAR; SOLOVIEVA, 2003). Nesse cenário, o conceito de atividade-guia ajuda a determinar o nível de desenvolvimento psicológico da criança. 


\subsection{Atividade guia na pré-escola}

Essa periodização proposta por Vygotski foi desenvolvida por Elkonin, que agregou às idades psicológicas etapas de desenvolvimento do jogo, discutindo em seu livro Psicologia do jogo, publicado originalmente em 1978, os seus efeitos sobre o desenvolvimento psíquico da criança (Lazaretti, 2013). O jogo, para Vigotskii, Luria e Leontiev (1988) e Elkonin (2009), é uma atividade objetiva, base da percepção que a criança tem do mundo e dos objetos humanos, utilizandoa para apropriação do mundo real. Torna-se uma atividade-guia quando o domínio de uma área mais ampla da realidade, que não é diretamente acessível à criança, só pode ser obtido, por meio dela.

Para Vygotsky (1998), o jogo cria uma ZDP, visto que contém tendências do desenvolvimento. Nas brincadeiras, as crianças apresentam comportamentos frequentemente mais avançados para a sua idade e aprendem a agir numa esfera cognitiva. Para Elkonin (2009), o jogo é tanto uma variedade de prática social, que permite reproduzir fenômenos da vida à margem do seu propósito real, como uma "escola de moral", visto que exerce grande influência no desenvolvimento psicológico da criança e na constituição de sua personalidade, o que pode ajudar a formar uma coletividade infantil bem ajustada quanto à relação entre as pessoas. Essa atividade é tão importante para o desenvolvimento infantil que constitui a atividade-guia dos períodos "Primeira infância" e "Pré-escolar" (SOLOVIEVA; QUINTANAR, 2012), portanto, entre o primeiro ano de vida e o sexto.

Elkonin (2009) estabelece cinco etapas de desenvolvimento do jogo, as quais trazem contribuições importantes desde os primeiros meses de vida até a idade "Escolar". A primeira delas é o jogo de manipulação inespecífica, correspondente ao "Primeiro ano". Esse jogo se desenvolve a partir dos 6 meses e evolui de modo intimamente relacionado com o desenvolvimento das coordenações sensório-motoras que permitem manipular e atuar com os objetos (Solovieva; Quintanar, 2012; Elkonin, 2009). Mediante essa atividade, a criança poderá conhecer os objetos, manipulando-os livremente. Executa ações 
denominadas “inespecíficas" porque ocorrem para qualquer objeto, independentemente de sua função social. Atendem a uma necessidade de estabelecer uma comunicação emocional com o adulto, o qual participa para ampliar as possibilidades de ação da criança, apresentar a ela novos objetos e animá-la a explorá-los (LAZARETTI, 2013; SOLOVIEVA; QUINTANAR, 2012).

$\mathrm{Na}$ "Primeira infância", ao final do primeiro ano, surge o interesse por aprender a manipular e utilizar os objetos humanos como instrumentos que têm uma função socialmente elaborada (Lazaretti, 2013). Sob a mediação do adulto, a criança obtém não só conhecimento prático, mas também o estímulo e o elogio (Elkonin, 2009). Assim, o jogo objetal se caracteriza pela realização de ações práticas correspondentes aos objetos cotidianos (SOLOVIEVA; QUINTANAR, 2014). Uma vez que a motivação para a ação está aliada à percepção, os objetos têm, inicialmente, uma força determinadora, a qual impulsiona a ação da criança, até que ela alcance a condição de agir independentemente daquilo que vê (VIGOTSKY, 2007).

Ainda nesse período, a partir dos dois anos, inicia-se o jogo simbólico, no qual as ações se generalizam e não mais requerem o objeto concreto para sua execução (Solovieva; Quintanar, 2012). Essa atividade se inicia pela possibilidade de substituir um objeto por outro dentro do jogo objetal, satisfazendo inicialmente uma necessidade de semelhança com o objeto representado, ainda que seu significado lúdico se altere. Nas idades psicológicas que seguem, esses objetos substitutivos ganham a capacidade de significar outros completamente discrepantes, a partir da abstração das características essenciais das coisas (ELKONIN, 2009). A imaginação da criança permite criar e representar diferentes ações e objetos em sua ausência. Ela poderá agir por modelos, bem como criá-los por si mesma (SOLOVIEVA; QUINTANAR, 2012; SOLOVIEVA; QUINTANAR, 1999). Esse jogo estabelece, portanto, as bases para o pensamento abstrato e para a atividade voluntária, o que requer autoconcentração e autodeterminação para o controle do impulso imediato (VIGOTSKY, 1998).

Na idade "Pré-escolar", a etapa correspondente é o jogo temático de papéis sociais. Nenhum outro jogo ressalta tanto as funções sociais e o sentido da 
atividade das pessoas como esse. O interesse da criança se volta ao adulto e seus atos, os quais são tomados como modelos. Há uma contradição entre as possibilidades reais que a criança tem de utilizar alguns objetos e o desejo de operar com aquilo que ainda não está ao seu alcance (SOLOVIEVA; QUINTANAR, 2012; ELKONIN, 2009). O jogo cria um mundo imaginário onde seus desejos não realizáveis podem ser satisfeitos (VIGOTSKY, 1998). Em contraposição à relação homem-objeto, sustentada pelas etapas de jogo anteriores, o predomínio da relação homem-homem é marca constituinte do jogo protagonizado (Elkonin, 2009), no qual a criança assume um papel social. Interpretar um papel significa realizar ações específicas ligadas a ele, estabelecida uma situação imaginária que contém regras de comportamento, ainda que não sejam predefinidas, nem explícitas (VIGOTSKY, 1998). A regra é delineada a partir do papel representado, no qual há um modelo de conduta implícito. Esse modelo oferece à criança a possibilidade de verificação da sua conduta, ainda que de forma não consciente (ELKONIN, 2009).

Esse jogo se estende por boa parte da infância, estando presente também na idade escolar, porém de forma mais complexa. Para melhor compreendê-lo, Elkonin (2009) dividiu, didaticamente, o desenvolvimento do jogo de papéis em dois estágios fundamentais. No primeiro estágio, correspondente à faixa etária de três a cinco anos, o jogo é determinado pelas ações objetais, de orientação social, correspondentes à lógica das ações reais. No estágio seguinte, entre cinco e sete anos, ele passa a ser delineado pelas relações sociais entre as pessoas e pelo sentido social de sua atividade. O que demarca a transição de um estágio a outro é a mudança do conteúdo fundamental do jogo, ou seja, daquilo que a criança reconstrói a partir de sua atividade com os adultos (ELKONIN, 2009). Todavia, a idade cronológica não é determinante, uma vez que crianças de uma mesma faixa etária podem estar em níveis distintos ou, até mesmo, em dois deles concomitantemente. 


\section{Neuropsicologia Histórico-cultural}

Glozman (2013) define que a Neuropsicologia do Desenvolvimento (também chamada "pediátrica") estuda a interação entre o funcionamento social de uma criança (comportamento e educação) e o desenvolvimento das suas funções mentais e personalidade, por um lado, e a maturação ontogenética do cérebro por outro, em condições normais e patológicas, assim como as possibilidades de utilizar esse conhecimento para a educação e (re)habilitação infantis.

A Neuropsicologia Histórico-cultural surgiu durante a II Guerra Mundial, na antiga União Soviética. Seu criador, Alexander Romanovich Luria, construiu suas bases teóricas e metodológicas baseando-se na Psicologia Histórico-cultural de Vigotsky (QUINTANAR; SOLOVIEVA, 2008). Fundamenta-se na teoria de que as funções psicológicas superiores do homem são sistemas complexos com propriedades especiais, que se caracterizam por serem sociais por sua origem, mediadas por sua estrutura, e voluntárias por sua natureza, além de apresentarem organização e estrutura dinâmicas (QUINTANAR, 1994). Sua formação durante a vida do indivíduo está socialmente condicionada (XOMSKAYA, 2002).

A Neuropsicologia proposta por Vigotsky e Luria busca as origens da consciência humana e da atividade mental na vida social humana, considerando que a estrutura do organismo pressupõe uma organização complexa de sistemas separados (GLOZMAN, 2007). Esta organização se expressa numa correlação funcional desses sistemas, que se unem como partes muito definidas, integradas em uma estrutura funcional. Isso significa que uma função psicológica superior compreende muitos componentes, sendo que cada um deles se baseia no trabalho de uma zona especial do cérebro e desempenha seu papel específico no sistema (GLOZMAN, 2007). Um sistema funcional complexo está integrado por diferentes setores cerebrais, cada um dos quais corresponde a diferentes componentes que integram uma função psicológica e é denominado "fator neuropsicológico" (ou "fatores lurianos"). Os sistemas funcionais apresentam estrutura e localização dinâmicas, o que significa que mudam com a idade e a aprendizagem. Assim, 
uma mesma função psicológica se localiza de maneira diferente na criança e no adulto ou em dois adultos, dependendo do grau de automatização (QUINTANAR; SOLOVIEVA, 2008).

O conceito de fator neuropsicológico pode ser compreendido como uma unidade funcional-estrutural que se caracteriza pelo princípio psicofisiológico de atividade e funcionamento. Refere-se, por um lado, a um determinado tipo de funcionamento cerebral produzido pelas redes neuronais de uma determinada zona do cérebro; por outro, tem um significado psicológico, pois é um importante componente do sistema funcional psicológico. A perturbação de um fator conduz à aparição de uma síndrome definida (GLOZMAN, 2007), ou seja, um conjunto de sintomas que surgem em diversas esferas da vida da pessoa, caracterizados pela debilidade daquele fator quando ele é recrutado por uma determinada atividade. O Quadro 2 apresenta os fatores neuropsicológicos, suas funções e participações nos sistemas funcionais da leitura e da escrita. Imaturidades no desenvolvimento de algum fator neuropsicológico tende a gerar dificuldades específicas caracterizadas pela falha no trabalho do fator em questão. A estimulação destes fatores busca garantir seu adequado funcionamento para a preparação da criança para a entrada na escola.

Quadro 2 - Fatores neuropsicológicos, suas funções e participações nos sistemas funcionais da leitura e da escrita.

\begin{tabular}{|l|l|l|l|}
\hline \multicolumn{1}{|c|}{ Fator } & \multicolumn{1}{|c|}{ Função do Fator } & \multicolumn{1}{c|}{ Leitura } & \multicolumn{1}{c|}{ Escrita } \\
\hline $\begin{array}{l}\text { Regulação e } \\
\text { controle }\end{array}$ & $\begin{array}{l}\text { Execução de uma tarefa de } \\
\text { acordo com o objetivo, } \\
\text { instrução ou regra } \\
\text { estabelecida. }\end{array}$ & $\begin{array}{l}\text { Regras de ortografia } \\
\text { e sintaxe; } \\
\text { compreensão do } \\
\text { sentido e significado. }\end{array}$ & $\begin{array}{l}\text { Escolha do tema e } \\
\text { das palavras, } \\
\text { organização das } \\
\text { ideias, aplicação } \\
\text { das regras. }\end{array}$ \\
\hline $\begin{array}{l}\text { Organização } \\
\text { sequencial motora }\end{array}$ & $\begin{array}{l}\text { Passagem fluente de um } \\
\text { elemento motor anterior para } \\
\text { a passagem flexível ao } \\
\text { posterior. }\end{array}$ & $\begin{array}{l}\text { Passagem fluída } \\
\text { entre letras, } \\
\text { palavras, frases e } \\
\text { ideias do texto. }\end{array}$ & $\begin{array}{l}\text { Produção } \\
\text { sequencial e fluida } \\
\text { dos elementos da } \\
\text { escrita. }\end{array}$ \\
\hline
\end{tabular}




\begin{tabular}{|c|c|c|c|}
\hline $\begin{array}{l}\text { Integração } \\
\text { fonemática }\end{array}$ & $\begin{array}{l}\text { Diferenciação dos sons verbais } \\
\text { do idioma dado de acordo com } \\
\text { as oposições fonemáticas. }\end{array}$ & $\begin{array}{l}\text { Decodificação grafema } \\
\text { fonema; diferenciação } \\
\text { de fonemas. }\end{array}$ & $\begin{array}{l}\text { Codificação } \\
\text { fonema-grafema; } \\
\text { diferenciação de } \\
\text { fonemas. }\end{array}$ \\
\hline $\begin{array}{l}\text { Análise e síntese } \\
\text { cinestésicas }\end{array}$ & $\begin{array}{l}\text { Sensibilidade tátil fina e } \\
\text { precisão de posturas; na } \\
\text { articulação da linguagem } \\
\text { garante a diferenciação dos } \\
\text { sons verbais de acordo com o } \\
\text { ponto e modo de produção } \\
\text { motora. }\end{array}$ & $\begin{array}{l}\text { Diferenciação de } \\
\text { fonemas. }\end{array}$ & $\begin{array}{l}\text { Traçado fino e } \\
\text { preciso das letras; } \\
\text { diferenciação de } \\
\text { fonemas. }\end{array}$ \\
\hline $\begin{array}{l}\text { Retenção áudio- } \\
\text { verbal }\end{array}$ & $\begin{array}{l}\text { Estabilidade das marcas } \\
\text { mnêmicas (volume de } \\
\text { percepção) na modalidade } \\
\text { audio-verbal, em condições de } \\
\text { interferência homo e } \\
\text { heterogênea. }\end{array}$ & $\begin{array}{l}\text { Arquivo das imagens } \\
\text { audio-verbais das } \\
\text { palavras; retenção do } \\
\text { conteúdo do texto. }\end{array}$ & $\begin{array}{l}\text { Arquivo das } \\
\text { imagens audio- } \\
\text { verbais das } \\
\text { palavras; retenção } \\
\text { do conteúdo do } \\
\text { texto. }\end{array}$ \\
\hline Retenção visual & $\begin{array}{l}\text { Estabilidade das marcas } \\
\text { mnêmicas (volume de } \\
\text { percepção) na modalidade } \\
\text { visual em condições de } \\
\text { interferência homo e } \\
\text { heterogênea. }\end{array}$ & $\begin{array}{l}\text { Arquivo das imagens } \\
\text { visuais das palavras; } \\
\text { retenção do conteúdo } \\
\text { do texto. }\end{array}$ & $\begin{array}{l}\text { Arquivo das } \\
\text { imagens visuais } \\
\text { das palavras; } \\
\text { retenção do } \\
\text { conteúdo do texto. }\end{array}$ \\
\hline $\begin{array}{l}\text { Perceptivo } \\
\text { analítico }\end{array}$ & $\begin{array}{l}\text { Percepção e produção } \\
\text { adequada de traços essenciais } \\
\text { e sua localização e as relações } \\
\text { espaciais entre os elementos. }\end{array}$ & $\begin{array}{l}\text { Análise da estrutura } \\
\text { espacial das letras e } \\
\text { palavras. }\end{array}$ & $\begin{array}{l}\text { Realização da } \\
\text { estrutura espacial } \\
\text { das letras e } \\
\text { palavras. }\end{array}$ \\
\hline Perceptivo global & $\begin{array}{l}\text { Percepção e produção } \\
\text { adequada da forma geral, dos } \\
\text { aspectos métricos e das } \\
\text { proporções de objetos. }\end{array}$ & $\begin{array}{l}\text { Estrutura espacial } \\
\text { global das letras e } \\
\text { palavras. }\end{array}$ & $\begin{array}{l}\text { Realização da } \\
\text { estrutura espacial } \\
\text { global das letras e } \\
\text { palavras. }\end{array}$ \\
\hline $\begin{array}{l}\text { Fundo geral de } \\
\text { ativação } \\
\text { inespecífico }\end{array}$ & $\begin{array}{l}\text { Garante o fundo e a } \\
\text { estabilidade da execução da } \\
\text { ação. }\end{array}$ & $\begin{array}{l}\text { Nível de alerta e } \\
\text { manutenção do tônus } \\
\text { de vigília. }\end{array}$ & $\begin{array}{l}\text { Nível de alerta e } \\
\text { manutenção do } \\
\text { tônus de vigília. }\end{array}$ \\
\hline $\begin{array}{l}\text { Fundo geral } \\
\text { emocional } \\
\text { inespecífico }\end{array}$ & $\begin{array}{l}\text { Garante o fundo e a } \\
\text { estabilidade emocional }\end{array}$ & $\begin{array}{l}\text { Motivação e } \\
\text { envolvimento com a } \\
\text { tarefa. }\end{array}$ & $\begin{array}{l}\text { Motivação e } \\
\text { envolvimento com a } \\
\text { tarefa. }\end{array}$ \\
\hline
\end{tabular}

Fonte: Adaptado de Quintanar e Solovieva (2008). 
A Neuropsicologia infantil de base histórico-cultural analisa o estado funcional dos setores cerebrais especializados e estabelece quais são os fatores neuropsicológicos fortes e débeis (QUINTANAR; SOLOVIEVA, 2000). Nesse processo, os testes psicométricos podem apenas lançar informação acerca do nível de rendimento de uma pessoa num atributo específico que, em ocasiões, é difícil de isolar e medir. Oferecem poucos dados necessários à intervenção. Luria avaliou o enfoque psicométrico e o qualificou como pouco eficaz na exploração do cérebro (SANTANA, 1999). Por outro lado, a avaliação neuropsicológica qualitativa implica a análise detalhada das execuções das tarefas propostas e se baseia na identificação dos tipos específicos de erros, as dificuldades e as particularidades das execuções da criança, assim como as formas e o grau de ajuda que a criança requer do avaliador (SOLOVIEVA; LÁZARO; QUINTANAR, 2008).

Akhutina (comunicação verbal5; 2012) ao uso das técnicas neuropsicológicas acrescenta o diagnóstico por observação, que consiste em observar se há ou não diferenças entre as crianças em relação ao seu grupo, incluindo a estrutura da atividade guia. Trata-se da observação do comportamento da criança dentro e fora do grupo, de como ela executa as diversas tarefas. Observa-se se há ou não diferenças entre eles.

Nesta perspectiva, os objetivos fundamentais da avaliação neuropsicológica infantil são: 1. Identificar as particularidades individuais do desenvolvimento de toda a esfera psíquica e da personalidade da criança; 2. Caracterizar o estado funcional dos mecanismos psicofisiológicos (fatores neuropsicológicos) para estabelecer as tendências, tanto negativas, como positivas, em sua formação; 3 . Identificar os sistemas funcionais que dependem do trabalho desses fatores que subjazem às ações e às operações incluídas nas atividades típicas para cada idade psicológica concreta; 4. Elaborar programas individuais de intervenção para fortalecer ou formar os aspectos funcionais débeis, a partir das atividades típicas da idade psicológica correspondente (QUINTANAR; SOLOVIEVA, 2003).

\footnotetext{
${ }^{5}$ Dra. Tatiana Akhutina, no III Seminario Internacional de Psicología, em Puebla (México), 2008. Palestra intitulada Evaluación y corrección neuropsicológica de las dificultades en la edad preescolar.
} 


\section{Convertendo a teoria em parâmetros práticos}

Um dos objetivos da psicologia e da Neuropsicologia Histórico-cultural é contribuir com o êxito da aprendizagem escolar (GONZÁLEZ-MORENO; SOLOVIEVA; QUINTANAR, 2012). Os conceitos apresentados até aqui permitem uma estreita colaboração prática entre a abordagem histórico-cultural (Psicologia e Neuropsicologia) e a Educação. Em primeiro lugar, essa abordagem aumenta a importância da escola e do educador ao demonstrar que o processo de ensinoaprendizagem estimula o desenvolvimento que permite a aprendizagem, numa constante relação dialética. Em segundo lugar, pode ajudar no estabelecimento de parâmetros e metodologias de trabalho para a promoção do desenvolvimento infantil, como: 1) Que tipo de estimulação cada criança precisa mais? 2) Como estabelecer objetivos para grupos e indivíduos? 3) Quais as atividades a serem empregadas e de que maneira? 4) Até que momento cada atividade é útil a cada criança?

Os métodos da abordagem histórico-cultural permitem a utilização da metodologia psicológica e neuropsicológica não só em sala de aula, mas em qualquer situação de contexto escolar e educacional. A investigação da ZDR possibilita conhecer a atividade-guia em exercício pela criança e o grau de desenvolvimento dos fatores neuropsicológicos. A análise da ZDP permite identificar o que ela pode adquirir num futuro mais imediato. $\mathrm{Na}$ medida em que se identificam suas necessidades, as neoformações para cada faixa etária podem ser alcançadas através da realização de atividades que objetivem estimular os fatores neuropsicológicos e os diferentes sistemas funcionais por meio da atividade-guia.

Ao longo da etapa pré-escolar, a atividade-guia seria o jogo de papéis. Assim, a investigação do modo como a criança brinca permite o estabelecimento dos parâmetros sobre as aquisições para a próxima etapa. Por exemplo, se uma criança, frente a pratos e talheres de brinquedo, apenas os manipula indistintamente (jogo de manipulação), mas pode, com a intervenção do adulto, utilizá-los a partir de suas identidades objetais (por exemplo, levando uma colher 
do prato à boca, como quem toma uma sopa), então se pode concluir que poderá adquirir os elementos da próxima etapa de maturação do jogo, a do jogo objetal, frente à estimulação do adulto. Este último assume, então, o papel de brincar e/ou organizar e orientar brincadeiras, garantindo a aquisição da etapa seguinte.

Um instrumento ${ }^{6}$ para investigação das características do jogo infantil foi desenvolvido na Faculdade Ruy Barbosa (FRB), em Salvador. O protocolo se propõe a avaliar o desenvolvimento da criança a partir da atividade de jogo, compreendendo suas etapas. Sua estrutura segue esse modelo processual e compõe-se de cinco etapas: 1. Avaliação da criança no primeiro ano; 2. Avaliação do jogo objetal; 3. Avaliação do jogo simbólico; 4 . Avaliação do jogo de papéis; 5. Avaliação do jogo de regras. As etapas se propõem a avaliar a atividade-guia de cada idade psicológica. O conteúdo do instrumento foi elaborado a partir de manuais e livros consultados (CORIAT, 1991; POBLANO, 2003; PÉREZ, 2009; ELKONIN, 2009; SOLOVIEVA; QUINTANAR, 2012). Além disso, algumas tarefas foram selecionadas e adaptadas a partir de protocolos de avaliação de préescolares menores (de 1 a 3 anos), elaborados por Solovieva e Quintanar (2014). A aplicação do instrumento permite identificar o período de desenvolvimento psicológico em que a criança se encontra para que se possa ajudá-la a alcançar as neoformações dessa etapa, preparando-a para a etapa seguinte.

Uma vez estabelecida a atividade-guia apresentada pela criança, o conteúdo de sua idade psicológica pode ser utilizado como mecanismo para estimular cada um dos fatores. Caso ela apresente a atividade de jogo objetal, por exemplo, durante o brincar, podem-se apresentar orientações verbais espaciais como "vamos colocar a mesa para o jantar: o garfo fica do lado esquerdo do prato e a faca do direito "; desta forma, estimula-se o fator perceptivo analítico (percepção e produção adequada de traços essenciais e sua localização e as relações espaciais entre os elementos).

A garantia da maturação dos fatores lurianos é um elemento importante (mesmo que não único) para a promoção do desenvolvimento e da aprendizagem das crianças porque eles compõem a formação de sistemas funcionais complexos,

\footnotetext{
${ }^{6}$ Autores: Caio Morais e Camila Borges. 
como os da linguagem oral, dos sistemas de memória, da leitura, da escrita e do cálculo, por exemplo. Pode-se observar o funcionamento dos diferentes fatores neuropsicológicos, por meio da análise do modo como cada criança realiza suas diversas atividades e tendo-se o grupo como referência. Conhecer o trabalho que cada fator realiza, assim como sua participação nos diversos sistemas funcionais e sua dinâmica, através do assim chamado "diagnóstico por observação", pode-se levantar hipóteses sobre o estado de maturação dos fatores em cada criança, em relação aos seus pares. A partir daí, pode-se pensar num rol de atividades a serem realizadas em contexto escolar (e até mesmo sugeridas à família) para estimular seu desenvolvimento e garantir a preparação para a entrada na escola. O Quadro 3 oferece um panorama geral sobre os fatores, o trabalho que realizam, como se apresentam em atividades concretas em caso de debilidade funcional e sugestões gerais de atividades para estimulação a título de exemplo.

Quadro 3 - Fatores neuropsicológicos, suas funções e zonas cerebrais correspondentes.

\begin{tabular}{|l|l|l|}
\hline \multicolumn{1}{|c|}{ Fator } & \multicolumn{1}{|c|}{ Debilidade } & \multicolumn{1}{c|}{ Sugestões } \\
\hline $\begin{array}{l}\text { Programação e controle da } \\
\text { atividade consciente }\end{array}$ & $\begin{array}{l}\text { Dificuldade em seguir as regras do } \\
\text { papel ao brincar com outras crianças; } \\
\text { Impulsividade ao realizar atividades } \\
\text { como quebra-cabeças etc. } \\
\text { Dificuldade em ser regulado pelo adulto. }\end{array}$ & $\begin{array}{l}\text { Vivo-morto; vivo-morto } \\
\text { com instrução conflitiva; } \\
\text { estátua; regulação do } \\
\text { adulto pela linguagem. }\end{array}$ \\
\hline $\begin{array}{l}\text { Organização sequencial dos } \\
\text { movimentos e ações } \\
\text { (melodia cinética) }\end{array}$ & $\begin{array}{l}\text { Dificuldades em aprender sequências } \\
\text { motoras: persevera um mesmo } \\
\text { movimento ou "trava" na passagem de } \\
\text { um a outro em atividades, como } \\
\text { Escravos de Jó. }\end{array}$ & $\begin{array}{l}\text { Dançar músicas como } \\
\text { Cabeça, Ombro, Joelho e } \\
\text { Pé; brincar de "adoleta", } \\
\text { de Escravos de Jó. }\end{array}$ \\
\hline $\begin{array}{l}\text { Integração fonemática } \\
\text { (ouvido fonemático) }\end{array}$ & $\begin{array}{l}\text { Problema de compreensão da linguagem } \\
\text { oral por dificuldade em diferenciar } \\
\text { fonemas do idioma, como na confusão } \\
\text { entre as palavras faca e vaca. }\end{array}$ & $\begin{array}{l}\text { Brincadeiras com rima, } \\
\text { aliterações e jogos com } \\
\text { palavras. }\end{array}$ \\
\hline $\begin{array}{l}\text { Análise e síntese } \\
\text { cinestésicas (integração } \\
\text { cinestésico-táctil) }\end{array}$ & $\begin{array}{l}\text { Controle motor fino imaturo podendo } \\
\text { gerar, por exemplo, um traço tremido no } \\
\text { desenho. }\end{array}$ & $\begin{array}{l}\text { Seu mestre mandou com } \\
\text { repetição de gestos, } \\
\text { trabalhar com texturas, } \\
\text { brincadeiras corporais } \\
\text { com olhos fechados. }\end{array}$ \\
\hline Retenção audio-verbal & $\begin{array}{l}\text { Dificuldade em recordar conteúdo audio- } \\
\text { verbal , como ordens, letras de músicas, } \\
\text { nomes etc. }\end{array}$ & $\begin{array}{l}\text { Músicas como "A árvore } \\
\text { da montanha"; seu } \\
\text { mestre mandou com } \\
\text { ordens verbais, com } \\
\text { crescimento crescente de } \\
\text { volume de informação. }\end{array}$ \\
\hline Retenção visual & $\begin{array}{l}\text { Dificuldade em lembrar as fichas em } \\
\text { jogo da memória, de aprender como } \\
\text { escreve seu nome ou lembrar onde ficam }\end{array}$ & $\begin{array}{l}\text { Jogo da memória e de "o } \\
\text { que está faltando?"; } \\
\text { desenho dirigido. }\end{array}$ \\
\hline
\end{tabular}




\begin{tabular}{|c|c|c|}
\hline & certos objetos. & \\
\hline Perceptivo analítico & $\begin{array}{l}\text { Perde muitos detalhes de imagens, } \\
\text { dificuldade em aprender } \\
\text { direita/esquerda, desenhos pobres em } \\
\text { detalhes e traços diferenciais. }\end{array}$ & $\begin{array}{l}\text { Jogo dos sete erros; } \\
\text { completar desenhos; onde } \\
\text { está Wally; tangram; } \\
\text { apresentação de uma } \\
\text { figura ou objeto modelo - } \\
\text { dentre outros objetos } \\
\text { para encontrar o modelo } \\
\text { em diferentes posições. }\end{array}$ \\
\hline Perceptivo global & $\begin{array}{l}\text { Não se orienta bem no espaço, não } \\
\text { interpreta imagens de forma esperada } \\
\text { por perder sua estrutura global, } \\
\text { evolução frágil do desenho. }\end{array}$ & $\begin{array}{l}\text { Caça ao tesouro; } \\
\text { construção de maquetes; } \\
\text { desenho de duas figuras } \\
\text { geométricas para que a } \\
\text { criança imagine que } \\
\text { figura poderia formar } \\
\text { com elas. }\end{array}$ \\
\hline $\begin{array}{l}\text { Fundo geral de ativação } \\
\text { inespecífico (tônus cortical) }\end{array}$ & $\begin{array}{l}\text { Hiperatividade ou lentidão, cansaço } \\
\text { anormal, dificuldade para reter } \\
\text { informações, perda de atenção. }\end{array}$ & $\begin{array}{l}\text { Organização da rotina } \\
\text { com horários fixos } \\
\text { principalmente para } \\
\text { dormir, acordar e soneca, } \\
\text { e observar melhor } \\
\text { horário para estudos; } \\
\text { atividade física regular; } \\
\text { intercalar atividades } \\
\text { menos ativas e mais } \\
\text { ativas. }\end{array}$ \\
\hline $\begin{array}{l}\text { Fundo geral emocional } \\
\text { inespecífico }\end{array}$ & $\begin{array}{l}\text { Desmotivação e falta de envolvimento } \\
\text { com a tarefa. }\end{array}$ & $\begin{array}{l}\text { Construir as tarefas com } \\
\text { os temas de interesse da } \\
\text { criança. }\end{array}$ \\
\hline
\end{tabular}

Fonte: Adaptado de Quintanar; Solovieva (2008).

Entretanto, apenas a estimulação dos fatores não é suficiente. É preciso também garantir que façam parte dos diversos sistemas funcionais. Desta forma, a Neuropsicologia Histórico-cultural oferece meios para acompanhar o desenvolvimento infantil em contexto escolar, através de métodos de avaliação adaptáveis a diferentes contextos e da observação; ademais, apresenta o que deve ser observado (o funcionamento dos fatores, dos sistemas, das atividades guia, da situação social de desenvolvimento e das neoformações) e de como se pode suprir as necessidades maturativas de cada criança (como escolher as atividades adequadas). Mas até que momento cada atividade é útil a cada criança?

A intervenção na ZDP permite parâmetros sobre o grau de utilidade de cada método de intervenção. Uma tarefa só é útil se intervir na ZDP, isto é: 1) sendo difícil o suficiente para que a criança não consiga realizá-la sozinha; e 2) não tão difícil a ponto de não conseguir completá-la com a ajuda de um adulto. Além disso, este deve dar a ela aquilo que é necessário para que, com o exercício, 


\section{Obütchénie}

ela seja capaz de fazer sozinha, alcançando autonomia. A isso Vigotsky (1998) chamou mediação, um processo que ocorre necessariamente entre ao menos duas pessoas, sendo que uma delas é mais experiente e apresenta o signo. Por sua vez, este último é um estímulo artificial, ou seja, criado pelo homem, que serve de meio para alcançar o domínio da própria conduta. Então, como conclusão, as atividades úteis como interventivas são aquelas que a criança não consegue fazer sozinha, mas sim com mediação. Na medida em que entra na ZDR, ou seja, que a criança adquire autonomia, a tarefa perde utilidade. Daí deve-se, então, aumentar sua dificuldade ou substituí-la por outra de maior exigência. No âmbito escolar, esse é o caminho para a promoção da autonomia do estudante, de modo que o professor atue como mediador de seu processo de aprendizagem e desenvolvimento, em um sentido mais amplo.

É importante considerar o conceito de "desenvolvimento desigual" das funções psicológicas. Cada criança, tanto na norma, quanto aquelas com dificuldades, caracteriza-se por um amadurecimento desigual das funções psicológicas. É um fenômeno normal que se determina pelo programa genético individual e pela experiência da criança em seu meio (AKHUTINA; PYLAEVA, 2012). Este conceito estabelece a noção essencial de que, apesar de o grupo de crianças que compõe a turma poder servir de referência para avaliação do nível geral de desenvolvimento de cada indivíduo, isto não significa que as capacidades das crianças devem ser iguais em todos os aspectos. Ou seja, através da observação em contexto escolar e a partir de parâmetros estabelecidos, como os aqui sugeridos, os profissionais podem perceber, comparando os alunos de uma turma entre si, quais apresentam determinadas habilidades em maior ou menor nível maturacional em relação aos demais.

A partir dos mesmos parâmetros, podem-se construir estratégias de ensino desenvolvimental para uma estimulação preventiva, a partir do pressuposto de que, se não ocorrer melhor maturação dessas habilidades, isso pode acarretar como consequência dificuldades durante o Ensino Fundamental. Entretanto, apesar de que a comparação grupal é útil para a investigação inicial, seu papel diminui durante o processo de estimulação e a análise dos resultados finais. Para estes, a comparação deve acontecer da criança com ela mesma, tendo-se como 
referência as Zonas de Desenvolvimento Real e Proximal. Ou seja, se aquilo que ela fazia em parceria com o adulto ao início do ano, ela já consegue fazer sozinha ao meio do ano - o que possibilita novos e mais complexos aprendizados -, isso aponta maior nível de desenvolvimento, mesmo que ainda não alcance o mesmo nível dos demais.

É possível oferecer um exemplo fictício. Imagine-se que, em determinada ocasião, chama a atenção de uma professora que uma garota parece ter mais dificuldade que os demais em completar um quebra-cabeça. Ao sentar para brincar com ela, percebe que sua aluna não tem atitudes impulsivas, não age de forma desorganizada durante a brincadeira e aparenta estar atenta ao que está fazendo, o que excluiria a necessidade de intervenção no fator neuropsicológico de regulação e controle. Por outro lado, com frequência escolhe a peça equivocada para determinado espaço, tem dificuldade em encontrar a posição correta para encaixá-la, não percebe a diferença entre aquelas mais centrais ou as das bordas. Todos equívocos relacionados à percepção espacial. Sugere, então, a hipótese de que talvez seja interessante uma maior estimulação dos fatores perceptivoanalítico e global. A professora passa a observá-la em outros contextos e percebe que ela tende a não se sair bem em brincadeiras de circuitos, por exemplo, nas aulas de Educação Física ou com o recreador, e que isso ocorre por perder-se no circuito ou não conseguir organizar seu corpo adequadamente frente aos obstáculos, o que corrobora sua hipótese inicial. Pede então, em algum momento, que realize um jogo de sombras, no qual a criança deve apontar qual sombra representa a figura modelo e percebe que consegue fazê-la, mas que necessita de ajuda. Esta ocorrência leva a professora a investigar a atividade-guia e observa que a garota aceita, sugere e organiza papéis, ajuda a estabelecer contextos para brincadeiras e as ações que realiza durante elas são adequadas aos papéis que assume. Assim, conclui que realiza jogos de papéis em seu último estágio. E pode propor brincadeiras em que, assumindo a aluna o papel de mãe, precise ir "de carro", seguindo um determinado roteiro escrito (como um mapa) para ir levar e buscar os filhos na escola. Se ela precisa da mediação da professora para realizar essa brincadeira e, junto com ela, consegue realizar o jogo, então essa proposta 


\section{Obütchénie}

estaria adequada a seu objetivo. Por outro lado, a professora também necessita ajudar a garota a desenvolver o jogo de regras, próxima etapa para maturação do jogo. Então, lhe ensina a brincar de amarelinha ou de elástico, por exemplo, e sugere à sua família que incentive o uso de jogos de mesa.

Ao mesmo tempo, tais necessidades não são necessariamente individuais. Programas pedagógicos para turmas inteiras podem basear-se, entre outros, nos parâmetros aqui apresentados. Outros programas podem ser oferecidos a pequenos subgrupos ou indivíduos específicos, sempre objetivando a preparação para o Ensino Fundamental e a consequente prevenção de problemas de aprendizagem. Para tanto, devem considerar o grau de desenvolvimento das neoformações básicas para a aprendizagem escolar, quais sejam: a atividade voluntária, atividade gráfica, a reflexão e a imaginação. Em geral, as crianças que apresentam um menor nível de desenvolvimento nesses aspectos, poderão apresentar problemas durante a aprendizagem de conteúdos da atividade escolar (GARCÍA, 2008). 


\section{Considerações finais}

A Neuropsicologia Histórico-cultural oferece instrumentos teóricos e práticos para o apoio ao desenvolvimento infantil e contribui para o estabelecimento de parâmetros para o trabalho com crianças, em diferentes contextos, bem como para a construção de ferramentas adequadas para investigação e estimulação. Os parâmetros aqui sugeridos não esgotam as possibilidades oferecidas por essa abordagem.

A concepção de desenvolvimento na Psicologia Histórico-cultural reitera a complexidade desse processo ao analisar suas etapas e características específicas, o que pode ter importância para os profissionais implicados na educação infantil. Esse conhecimento instrumentaliza os professores para trabalhar na ZDP dos estudantes, sempre impulsionando seu desenvolvimento, construindo autonomia e motivação pelo estudo e prevenindo possíveis dificuldades no processo escolar de ensino-aprendizagem. Considera-se que a assimilação das ideias aqui apresentadas, por parte dos profissionais da educação, ao longo da sua formação, colabora com a construção de uma escola estimuladora e preventiva, diminuindo a necessidade do encaminhamento para serviços externos e aumentando a importância da educação infantil. Dessa forma, os professores dos anos iniciais deveriam receber maior atenção em relação ao que acontece atualmente e maior incentivo, traduzido em melhor formação (que deveria incluir maior conhecimento e preparação prática para sua aplicação) e em remuneração mais justa.

Uma ferramenta muito útil à prevenção de dificuldades de aprendizagem é o conhecimento das características da etapa de desenvolvimento em que a criança se encontra, admitindo-se inclusive que não haverá uma uniformidade em termos de idade psicológica entre todos os alunos que integram uma mesma turma. Porém, saber qual a atividade-guia que favorecerá o desenvolvimento dos fatores neuropsicológicos e a aquisição de uma série de novas competências e habilidades, dentro de uma determinada idade psicológica, ajuda o professor a 


\section{Obutchénie}

estimular seus alunos com atividades específicas e orientadas para seu melhor aproveitamento.

\section{Referências}

AKHUTINA, T.; PYLAEVA, N. Overcoming learning disabilities: A vygotskianlurian neuropsychological approach. Cambridge: Cambridge University, 2012. $305 \mathrm{p}$.

BRASIL. Ministério da Educação. Base Nacional Comum Curricular. Brasília, DF: 2017. Disponível em:

$<$ http://basenacionalcomum.mec.gov.br/\#/site/relatoriosanaliticos>. Acesso em: 7 dez. 2017.

BRASIL. Ministério da Educação. Parâmetros Curriculares Nacionais para o Ensino Médio. Brasília, DF: 2000. Disponível em:

<http://portal.mec.gov.br/seb/arquivos/pdf/blegais.pdf:. Acesso em: 7 dez 2017.

CORIAT, Lydia F. Maturação psicomotora no primeiro ano de vida da criança. São Paulo: Moraes, 1991. 184 p.

DAVIDOV, V. La enseñanza escolar y el desarrollo psíquico. Moscú: Editorial Progreso, 1988.

ELKONIN, D. B. Psicologia do jogo. São Paulo: Martins Fontes, 2009. 443 p.

GARCÍA, E. L. Identificación temprana de dificultades para la actividad escolar. In: QUINTANAR, L. et al. Dificultades en el proceso lectoescritor. Valladolid : Editorial de la Infancia, 2008.

GLOZMAN, J. Developmental neuropsychology. New York: Routledge, 2013. 215 p.

GLOZMAN, J. M. A.R. Luria and the history of Russian neuropsychology. Journal of the History of the Neurosciences, n.16, p.168-180, Feb. 2007.

GONZÁLEZ-MORENO, C. X.; SOLOVIEVA, Y.; QUINTANAR, L.

Neuropsicología y psicología histórico-cultural: Aportes en el ámbito educativo. Revista de la Facultad de Medicina, v. 60, n. 3, p. 221-231, Sep. 2012.

LAZARETTI, L. M. Daniil Borisovich Elkonin: A vida e as produções de um estudioso do desenvolvimento humano. In: LONGAREZI, A.M.; PUENTES, R.V. Ensino desenvolvimental: Vida, pensamento e obra dos principais representantes russos. Uberlândia: EDUFU, 2013. p. 203-231. 
LEONTIEV, A. N.et al. Os princípios do desenvolvimento mental e o problema do atraso mental. In: Psicologia e pedagogia: bases psicológicas da aprendizagem e do desenvolvimento. São Paulo: Centauro, 2005. p. 59-76.

PÉREZ, M. C. S. Valoración neuroconductual del desarrollo del lactante. México, DF: CBS, 2009. 50 p.

POBLANO, Adrián. Detección y estimulación tempranas del niño con daño neurológico. México, DF: ETM, 2003. 277 p.

QUINTANAR, L. La escuela neuropsicológica soviética. In: QUINTANAR, L. Modelos neuropsicológicos en afasiología: aspectos teóricos y metodológicos. Puebla: Benemérita Universidad Autónoma de Puebla, 1994. p. 25-59.

QUINTANAR, L.; SOLOVIEVA, Y. Aproximación histórico-cultural: fundamentos teórico-metodológicos. In: ESLAVA-COBOS, J. et al. (Ed.) Los trastornos del aprendizaje: perspectiva neuropsicológica. Bogotá: Cooperativa Editorial Magisterio; Instituto Colombiano de Neurociencias; Benemérita Universidad Autónoma de Puebla, 2008. p. 147-172.

QUINTANAR, L.; SOLOVIEVA, Y. La discapacidad infantil desde la perspectiva neuropsicológica. In: CUBILLO M.A.; GUEVARA J.; PEDROZA A. Discapacidad humana, presente y futuro. El reto de la rehabilitación en México. Tlaxcala: Universidad del Valle de Tlaxcala, 2000. p. 51-63.

QUINTANAR, L.; SOLOVIEVA, Y. Manual de evaluación neuropsicológica infantil. México: Benemérita Universidad Autónoma de Puebla. 2003. 208 p. SANTANA R.A. Aspectos neuropsicológicos del aprendizaje escolar. San Juan de Puerto Rico: Innovaciones Psicoeducativas, 1994. 231 p.

SOLOVIEVA, Y.; LÁZARO, E.; QUINTANAR, L. Aproximación históricocultural: Evaluación de los trastornos de aprendizaje. In: ESLAVA-COBOS, J. et al. (Ed.) Los trastornos del aprendizaje: perspectivas neuropsicológicas. Bogotá: Cooperativa Editorial Magisterio; Instituto Colombiano de Neurociencias; Benemérita Universidad Autónoma de Puebla, 2008. p. 183-222.

SOLOVIEVA, Y.; QUINTANAR, L. Evaluación del desarrollo para niños preescolares menores. Puebla: Benemérita Universidad Autónoma de Puebla, 2014, 86 p.

SOLOVIEVA, Y.; QUINTANAR, L. La actividad de juego en la edad preescoolar. México DF: Trillas, 2012. 142 p.

TOOMELA, A. There can be no culturalhistorical psychology without neuropsychology. And vice versa. In: YASNITSKY, VAN DER VEER, R.; FERRARI, M. (Eds.) The Cambridge Handbook of Cultural-Historical 


\section{Obütchénie}

Psychology. Cambridge: Cambridge University Press, 2014. p. 315-349.

VAN DER VEER, R.; VALSINER, J. Teoria histórico-cultural. In: Vygotsky: uma síntese. São Paulo: Edições Loyola, 2014, p. 207-265.

VIGOTSKI, L. S. A formação social da mente. São Paulo: Martins Fontes, 1998. $191 \mathrm{p}$.

VIGOTSKII, L. S.; LURIA A.R.; LEONTIEV, A. N. Linguagem, desenvolvimento e aprendizagem. São Paulo: Ícone. 1988, 228 p.

VIGOTSKY, L. S. A psique, a consciência, o inconsciente. In: VIGOTSKY, L. S. Teoria e método em psicologia. São Paulo: Martins Fontes, 2004. p. 137-159.

VIGOTSKY, L. S. Obras escogidas. Madrid: Visor , 1995. v.3, 383 p.

VIGOTSKY, L. S. Obras escogidas. Madrid: Visor, 1996. v. 4, 427 p.

VILA, I. Lev S. Vigotsky: la psicología cultural y la construcción de la persona desde la educación. Cidade: Graó Editorial, 2001. p . 207-227.

VYGOTSKI, L. S. El significado histórico de la crisis de la psicología. Una investigación metodológica. In: VYGOTSKI, L. S. Obras Escogidas. Madrid: Machado Nuevo Aprendizaje, 2013. v. 1, p. 259-407.

XOMSKAYA, E. El problema de los factores. Revista Española de Neuropsicología, v. 4, n. 2-3, p. 151-167, set. 2002.

ZAPOROZHETS, A. V. La importancia de los periodos tempranos de la infancia para la formación de la personalidad infantil. In: ILIAZOV; LIAUDIS. Antología de la psicología pedagógica y de las edades. Ciudad de la Habana: Pueblo y Educación, 1986. p. 148-151. 